\title{
Evaluation of APi Interface Design by Applying Cognitive Walkthrough
}

\author{
Nur Atiqah Zaini ${ }^{1}$, Siti Fadzilah Mat Noor ${ }^{2}$, Tengku Siti Meriam Tengku Wook ${ }^{3}$ \\ Faculty of Technology \& Information Science \\ Universiti Kebangsaan Malaysia, 43600 Bangi, Selangor Malaysia
}

\begin{abstract}
The usability evaluation of APi interface design was conducted through Cognitive Walkthrough method. APi is a mobile application game designed specifically for preschool children of Tabika Kemas Kampung Berawan, Limbang Sarawak in order to learn about fire safety education. The existing fire safety games have few interaction styles issues and interface design tested on preschool children. A key ingredient to promote the preschool children to learn basic skills of fire safety is by providing them an interactive learning as the new learning method. Low-fidelity of APi prototype was designed based on the user requirements of the preschool children focusing on cognitive, psychomotor and behaviour aspects. This Cognitive Walkthrough method applied on APi interface design involved a small group of professional designers and developers. As a result, the high-fidelity of APi prototype interface design was developed for the preschool children.
\end{abstract}

Keywords-Cognitive Walkthrough; interface design; usability evaluation

\section{INTRODUCTION}

APi prototype was developed for preschool children to learn and stimulate their brains through gaming environment towards the fire safety issues at the early ages. The use of tablet technology in teaching and learning APi supported the educational activities. Advances in technology that have led the teaching and learning methods aroused children's attention where they were showing interests during learning session [1]. With the education system under growing pressure to deliver high quality of learning through edutainment, gaming elements are added as the factor of motivation in learning session [2], [3], [4]. Conveying the information of fire safety to the preschool children with the use of tablet technology can help in improving their skills, cognitive and behaviour. It shows that tablet technology has a great potential in providing information that can easily increase the children's engagement to focus on edutainment [5], [6].

In order to achieve the usability of APi prototype interface design, a Cognitive Walkthrough method was conducted which involved a small group of professional designers and developers [7]. Among its function, APi prototype provided three main missions that required the users to play, solve and complete all stages. Each page of APi interface were designed based on menu driven that guided the users easily and systematically. By conducting Cognitive Walkthrough method, few problems regarding the interface design and functionality were identified. However, when Cognitive Walkthrough session conducted, it did not require the fully functioning system or application needed. Thus, the system or application itself will be improved to develop the high-fidelity prototype at the next stage of development. The process of Cognitive Walkthrough helped in obtaining the problems occurred in the APi interface design. The main objective of this research was to carry out the Cognitive Walkthrough method in evaluating the APi prototype interface design based on the requirements of preschool children.

Youth especially preschool children are highly exposed towards fire hazard at home, school or building. The fact that smoke alarms alerted the people to escape from fire in an emergency situation helped to save them from death and injuries [8]. Fire would spread rapidly over flammable surfaces causing the strong heat that lead the children into danger. Losing vision and difficulty breathing were the causes of injuries that led to death. According to the annual report of Fire and Rescue Department of Malaysia, home was the highest fire cases reported which was 1263 cases in 2016, followed by terrace house which showed 921 cases and flat house, 331 cases [9].

Children mostly spend time at home, which concluded that they need to be exposed to fire safety education. By providing the medium of teaching and learning about fire safety education through media, awareness programs and edutainment, children would obtain knowledge on the basic skills to escape fire eventually. Advances in technology and its use in education stimulated the children's creativity which arouses their attention during learning session [1], [10]. Technology provides interactive tools and applications for children to engage them in learning. Thus, the use of technology itself such as tablet attracts the children to explore more. In fact, the technology in the form of touch provided new interaction style as touch interaction that brings excitement to the users.

There were lots of applications and serious games developed in order to learn the fire safety education. The awareness of fire safety should be started an early age to reduce death and injuries. Virtual reality has been used as learning tool to simulate fire safety situations [11]. By using immersive virtual reality with the used of CAVE, game pad and 6DOF wand immersed children in a fire scene. Virtual reality helped in reducing danger to practice real fire situation. Thus, the results indicated that the children were engaged well and experienced fun in fire safety skills training. Virtual reality has the potential to improve effectiveness over prior fire training methods and reduce risk of injuries on users. In general, the design of effective virtual reality of training was considered. 
Other than that, the learning outcomes of fire safety education showed that computer games could be an effective way of learning fire safety education [12]. Gaming environment promoted the children's understanding and responses in hazardous situations. The Great Escape was developed for children to play the game that provided activities. With minimal adult supervision and no reading requirement needed, the children were able to play it alone. The related study evaluated the effectiveness of interactive computer game to learn fire safety education. It proved that through gaming environment improved the knowledge and behaviours of children.

In addition, the immersive simulation training system helped the children to learn through gesture interaction using Microsoft Kinect and large screen display environment [13]. It showed that the improvements of escape skills of the children experiencing simulation training system. Therefore, it provided three modules such as animation, quizzes and a 3D serious game that stimulated their brains in solving problems. In addition, animation and games were used to attract the children's attention. Thus, animation has the biggest impact in industries such as entertainment and education. Computer animation was a practical tool that used to explain theory and concepts of fire safety to children in a more convincing way.

However, the applications or games developed must be considered for preschool children's requirements in terms of cognitive, psychomotor and behaviour. The preschool children are still in the process of growth development [14]. Children have difficulties in controlling their hands and fingers because of weak muscles [15]. Therefore, the lack of knowledge and awareness towards fire hazard were the main reasons to learn fire safety education [16]. Yet the approaching method to educate the children should not only focus on conventional learning but also provide them the platform of interactive learning using technologies. These will improve their knowledge as well as psychomotor skills and behaviour such as response in conceptualizing the fire hazard. Different interaction styles are needed to immerse and engage the children in learning session eventually.

Meanwhile, the Cognitive Walkthrough method had been implemented for years to evaluate the user interface designs. This method enhanced the usability of the system developed because of the difficulties in interaction and interface design problems occurring on the existing systems. Therefore, evaluation of interface design could be done at the early stage of system development to configure and meet the user requirements.

The process of Cognitive Walkthrough focused on evaluating the usability of a system for ease of learning through exploration by the respondents [17]. This method involved the experts, which consisted of one or a group of respondents. These respondents have different type of background for testing the system. Cognitive Walkthrough was one of the most-adopted expert-based methods to practice the usability evaluation. By conducting Cognitive Walkthrough, it did not require a fully functioning prototype as well as the involvement of real users [18]. Thus, it helped the developers or designers to identify the problems of interface design that occurred in the interaction of system.

The Cognitive Walkthrough tasks were provided to the respondents to achieve goals by completing the tasks. Conducting Cognitive Walkthrough method on the system, it examined the correct actions done by the users that required them to accomplish the tasks eventually. Each part in the system that confused the users will be identified and improved by designing the interface to ease the users to keep them engaged with the system. The failure of the system would cause the delay in conveying information and affect the users too in terms of satisfaction and user experiences.

In recognition of fire safety education, APi prototype was developed to provide interactive learning for preschool children. The APi interface design evaluated through Cognitive Walkthrough method is to identify the weakness and problems occurred on the interface design. Few procedures were followed to conduct the process of APi interface design evaluation. Next, the topic will be discussed further on the development of low-fidelity and high-fidelity APi prototype based on preliminary study to obtain user requirements, model developed and the process of Cognitive Walkthrough conducted.

\section{MethoD}

APi interface design was developed based on the Model of Game-Based Learning in Fire Safety for preschool children through the method of User-Centered Design. Firstly, the development of model was obtained based on preliminary study conducted to acquire the user requirements [19]. During the preliminary study, there were two types of existing fire safety games tested on the preschool students. Few interaction styles issues in the existing games of "Help Mikey Make It Out" and "Fire Safety Challenge" were being investigated by using tablet technology. These existing games were analyzed specifically on interaction styles and interface design.

\section{A. Preliminary Study of APi Interface Design}

As shown in Table 1, there were few issues of interaction investigated after being tested on the preschool children along with the description of the games.

TABLE I. The Preliminary Study of EXISTING Fire SAFETy GameS

\begin{tabular}{|c|c|c|}
\hline $\begin{array}{l}\text { Type of } \\
\text { Games }\end{array}$ & Initial Investigation & Issues of Interaction (Users) \\
\hline $\begin{array}{l}\text { Help Mikey } \\
\text { Make It Out }\end{array}$ & $\begin{array}{l}\text { 1. Limited user interaction. } \\
\text { 2. Lack of information. } \\
\text { 3. Use of language } \\
\text { 4. Less guidelines } \\
\text { provided. }\end{array}$ & $\begin{array}{l}\text { 1. User only interacted with } \\
\text { limited button. } \\
\text { 2. The interface was quite } \\
\text { confusing for the users. } \\
\text { 3. Less instruction for the } \\
\text { users on how to play. } \\
\text { 4. Difficulty in } \\
\text { understanding English. }\end{array}$ \\
\hline $\begin{array}{l}\text { Fire Safety } \\
\text { Challenge }\end{array}$ & $\begin{array}{l}\text { 1. Lack of information. } \\
\text { 2. Element of sound or } \\
\text { voice used. } \\
\text { 3. Use of language. }\end{array}$ & $\begin{array}{l}\text { 1. No guidelines on how to } \\
\text { play. } \\
\text { 2. No instructions through } \\
\text { voice provided. } \\
\text { 3. Difficulty in } \\
\text { understanding English. }\end{array}$ \\
\hline
\end{tabular}


TABLE II. USER REQUIREMENTS

\begin{tabular}{|c|c|c|c|}
\hline User Requirements & 4 years & 5 years & 6 years \\
\hline 1. User Interaction & $\checkmark$ & $\checkmark$ & $\checkmark$ \\
\hline 2. Interface Design & $\checkmark$ & $\checkmark$ & $\checkmark$ \\
\hline $\begin{array}{l}\text { 3. Psychomotor (Fine } \\
\text { Motor) }\end{array}$ & $\checkmark$ & $\checkmark$ & $\checkmark$ \\
\hline 4. Cognitive (Knowledge) & $\checkmark$ & $\checkmark$ & $\checkmark$ \\
\hline 5. Behaviour & $\checkmark$ & $\checkmark$ & $\checkmark$ \\
\hline $\begin{array}{l}\text { 6. Gaming elements } \\
\text { (Reward, Storyline, } \\
\text { Player, Time, } \\
\text { Multimedia Components, } \\
\text { Genre) }\end{array}$ & $\checkmark$ & $\checkmark$ & $\checkmark$ \\
\hline $\begin{array}{l}\text { 7. Multimedia Component } \\
\text { (Animation \& Audio) }\end{array}$ & $\checkmark$ & $\checkmark$ & $\checkmark$ \\
\hline 8. Malay Language & $\checkmark$ & $\checkmark$ & $\checkmark$ \\
\hline
\end{tabular}

After identifying the interaction issues on preschool children when using the existing fire safety games, the collected data can be implemented in developing the model of game-based learning in fire safety. The existing games tested on the preschool children showed the user requirements obtained as shown in Table 2.

Meanwhile, Fig. 1 showed the model used in the research after conducting preliminary study to obtain the user requirements. The model of game-based learning of fire safety was used in developing the low-fidelity prototype and highfidelity prototype based on the user requirements obtained. The target user was preschool children at the age of four to six years' old who can handle the technology of tablet to learn fire safety education.

APi fire safety game has few game elements added such as rewards, player, storyline, feedback, multimedia components and game genre [20]. These elements are needed by the preschool children to bring motivation, enjoyment and interactivity [21]. While, the interface design is using menudriven with animation and audio focused to develop the game. The voiceover used is in Malay language where the users easily understand the instructions given.

In this paper, the cognitive walkthrough method was carried out to evaluate the low-fidelity APi prototype interface design. This method was evaluated on six expert users. While after the evaluation of low-fidelity prototype, the data collection was implemented in developing high-fidelity prototype for the final stage of development. Thus, the evaluation of effectiveness will be verified on the real users who are preschool students.

Through the final evaluation of high-fidelity prototype using observation and think aloud techniques on preschool children, there are three aspects being evaluated too. This future work will be evaluated specifically among four to six years old children. It consists of cognitive, psychomotor and behaviour of the preschool children. Based on cognitive abilities, the children will be tested by giving three missions to be accomplished in a limited time. They need to figure out solutions to solve all the missions given. Meanwhile, psychomotor skills are focusing on fine motor skills where they need to use touch interaction. They will be observed on how well they can control the speed and game controller buttons provided. Lastly, their behaviours through the gameplay will be evaluated before, during and after playing the game.

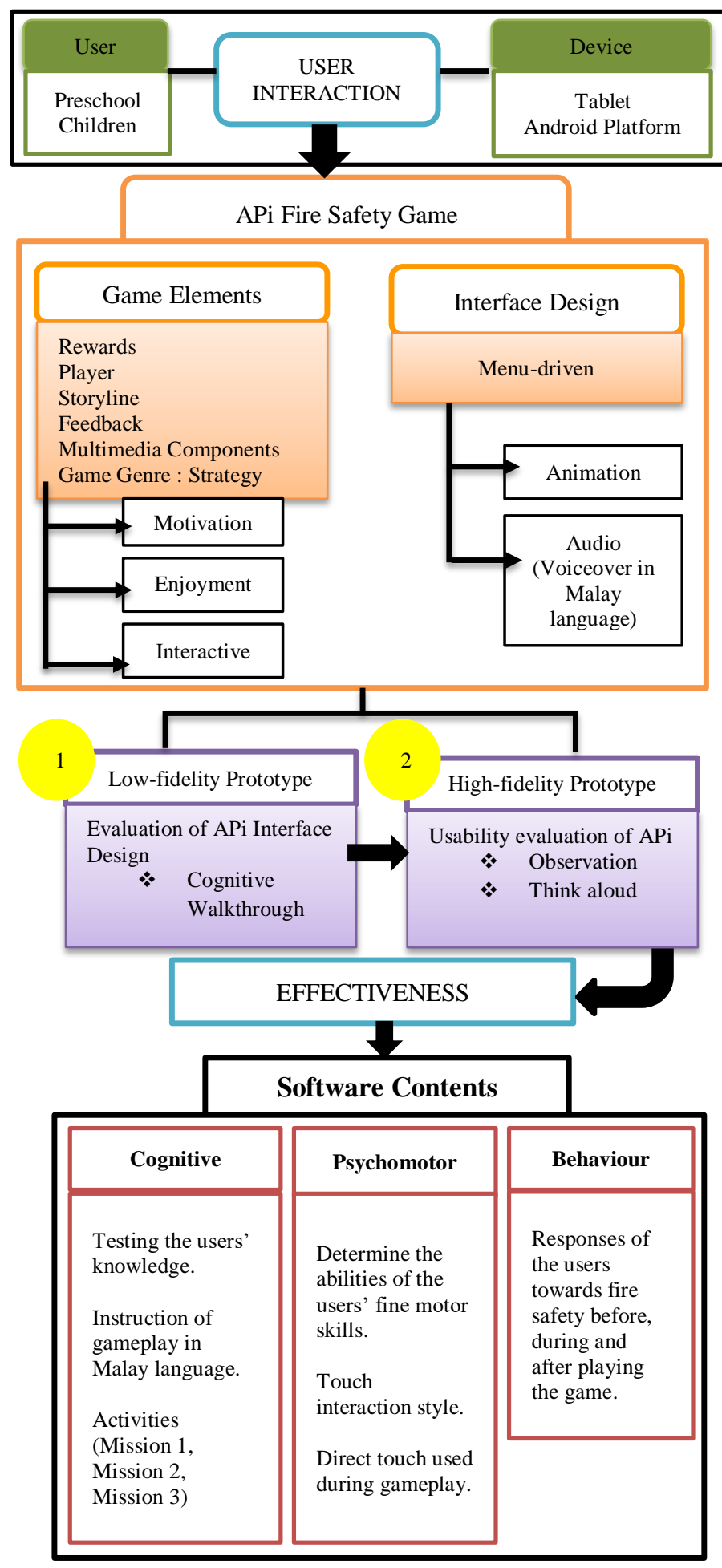

Fig. 1. Model of Game-based Learning in Fire Safety for Preschool Children. 


\section{B. Low-Fidelity APi Prototype}

A low-fidelity APi prototype was developed based on the Model of Game-Based Learning in Fire Safety. In fact, the objective of developing APi prototype was to implement the model developed for preschool children. As mentioned during preliminary study, APi interface design emphasized more on the interaction style issues which is needed by the users to understand about fire safety education. This is achieved by providing the action buttons and the used of multimedia components such as audio and animations in the APi prototype development which were required in the model developed. These were the low-fidelity APi prototype interfacre design as shown in Table 3 that represented the activities and information for the users.

TABLE III. API PROTOTYPE INTERFACE DESIGN

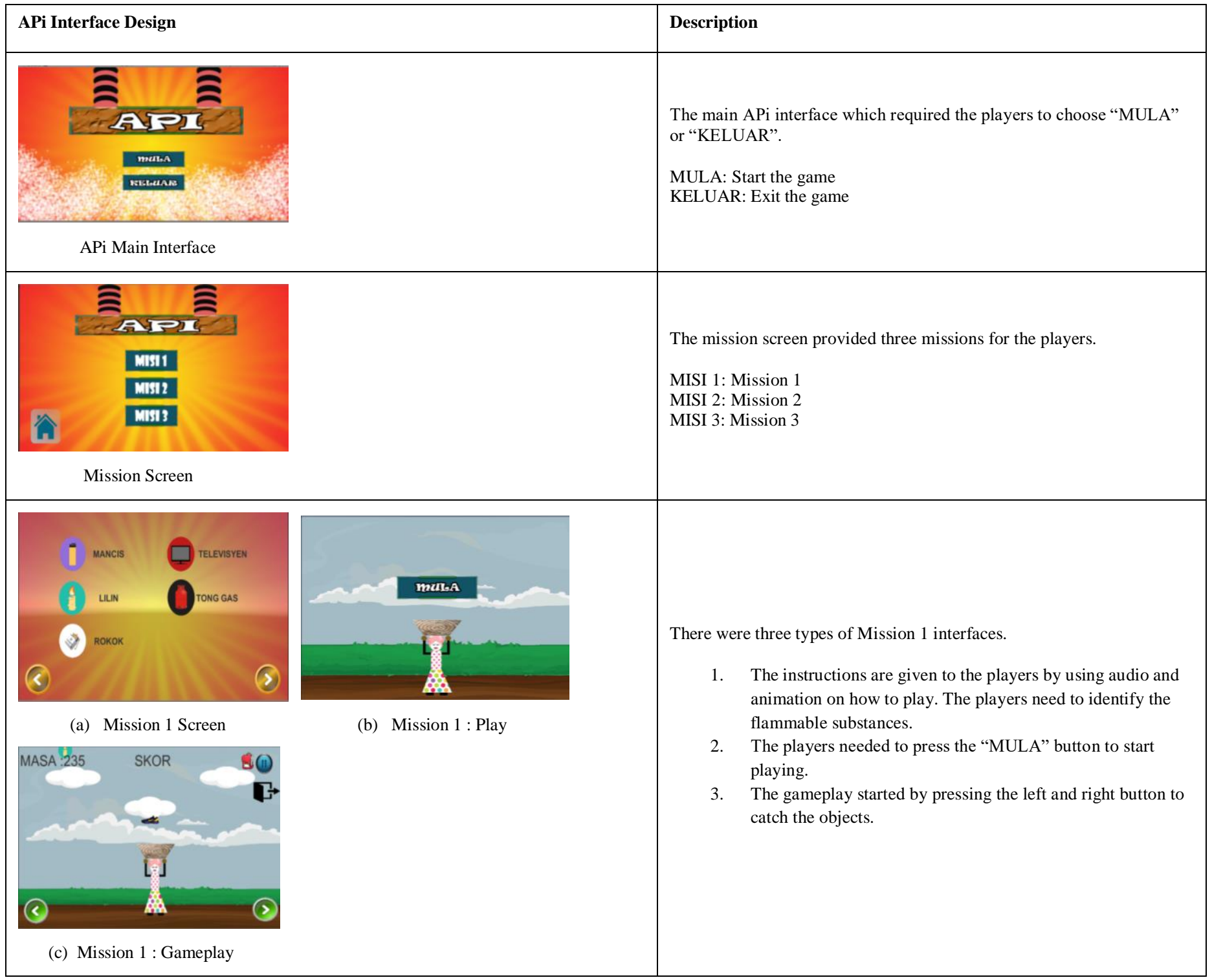

Strategic Research Grant of KRA-2018-025, Faculty of Technology \& Information Science, Universiti Kebangsaan Malaysia. 


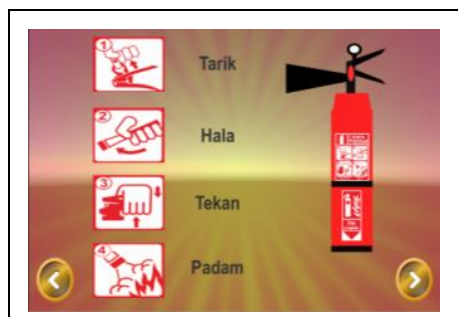

(a) Mission 2 Screen

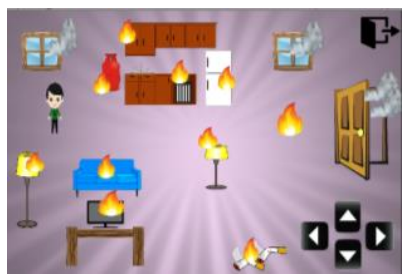

(c) Mission 2 : Gameplay

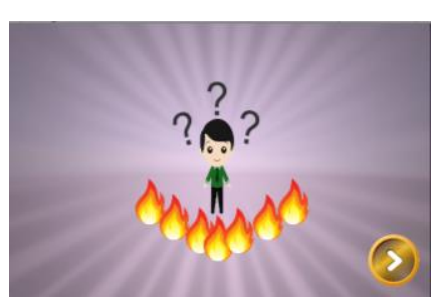

(b) Mission $2:$ Instruction

There were three types of Mission 2 interfaces.

1. Giving the information on how to handle fire extinguisher through audio and animation.

2. The instructions are given to the players by using audio on how to play. The players need to think on how to escape from the house with fire.

3. The gameplay started when pressing the next button and the users will start to play. There were four buttons provided for the players to move the character.

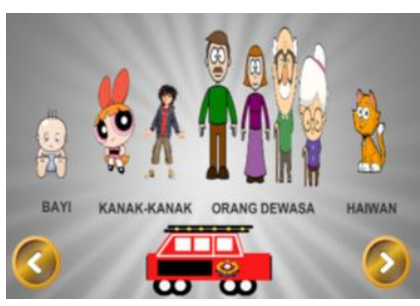

(a) Mission 3 Screen

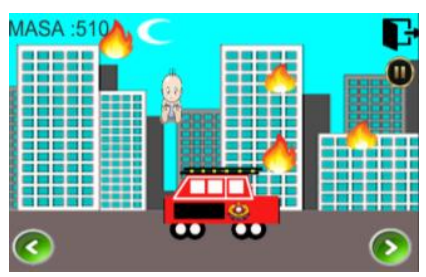

(c) Mission 3 : Gameplay

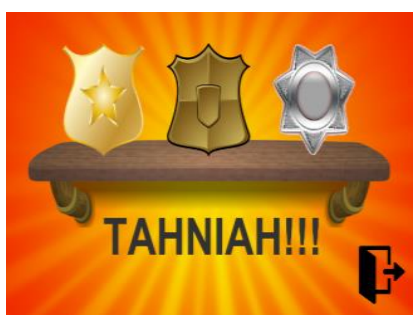

Reward Screen

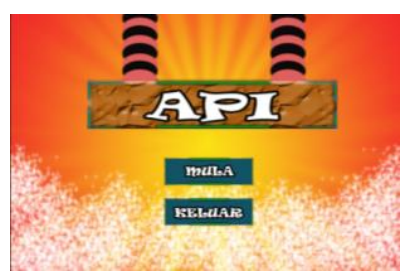

(a) APi Main Interface

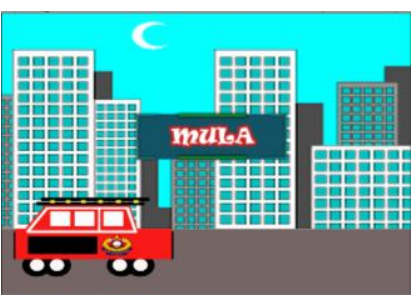

(b) Mission 3 : Play
There were three types of Mission 3 interfaces.

1. The instructions are given to the players by using audio on how to play. The players needed to identify who were the important ones to save from fire.

2. Pressing the "MULA" button to start playing.

3. Pressing the right and left button to move the character to catch the targeted objects.

The rewards for the players after completing all of the missions given.

These screens enabled the players to exit the game. 


\section{Cognitive Walkthrough}

The Cognitive Walkthrough method used in evaluating the APi prototype interface design which involved six participants. Those participants were experts, two lecturers, two gamers and two graphic designers that give critical comments on the APi interface design. This process performed by the users for about 20 minutes where they were not allowed to discuss anything with other participants during the session. Along with the comments, there were specific tasks provided for the participants to be carried out. The evaluation process involved four phases, which were:

1) Phase 1: Will the user try to achieve the right effect?

Description: The achievement of objectives/goals in playing APi prototype by the users to accomplish the missions

Example: Reading the instructions provided in the game to achieve the goals.

2) Phase 2: Will the user notice the correct action button is available?

Description: The provided action button in the game for the users.

Example: Start button, exit button, next button, left and right button.

3) Phase 3: Will the user associate the correct action with the effect to be achieved?

Description: The users are allowed to choose the mission and exploring on the game itself.

Example: Identifying the escape route during evacuation when fire spread in the building.

4) Phase 4: Will the user move forward with to progress the tasks if the correct action is performed?

Description: The users do the tasks given and look through on how the APi prototype responds to them.

Example: Pressing the Start button and directly accessing the mission page.

\section{Procedures of Cognitive Walkthrough}

All the procedures should be followed by the participants during the Cognitive Walkthrough session conducted.

1) The participants are given 20 minutes to operate the low-fidelity APi prototype.

2) The participants are not allowed to discuss among them before and after the Cognitive Walkthrough session.

3) During the session, all the participants are strictly reminded not to get involved in other activities in order to avoid interruption of APi prototype testing.

4) All participants are required to understand all the conditions, tasks given, rules and action taken before, during and after the session.

These were the specific tasks provided to the users along with the APi low-fidelity prototype. The tasks were shown below:
The participant needs to press the button "MULA" at the APi main interface to start the game.

1) Next, the participant needs to choose "MISI 1" as the starting mission. The instruction will be given through audio before the mission starts. The participant needs to test the functionality of the button to proceed to the next screen.

2) The participant starts the "MISI 1" by pressing the "MULA" button and play the game. Then, the left and right button are provided to move the character after the instructions are given through audio.

3) After completing the "MISI 1", the participant can go to the mission screen by hitting the "OUT" button provided at the right side.

4) The participant will choose "MISI 2" for the next game. The instructions will be given through audio to guide the participant. There will be RIGHT and LEFT button provided to go to the next page.

5) The participant will be given instructions on how to play by using UP, DOWN, LEFT and RIGHT button provided.

6) After completing the "MISI 2", the participant can go to the mission screen by hitting the "OUT" button provided at the right side.

7) Next, the participant needs to choose "MISI 3" and the instruction will be given through audio before the mission has started. The participant needs to test the functionality of the button to proceed to the next screen.

8) The participant starts the "MISI 3" by pressing the "MULA" button and play the game. Then, there are RIGHT and LEFT button provided to move the character after the instructions given through audio.

9) After completing the "MISI 3", the participant can go to the mission screen by hitting the "OUT" button provided at the right side.

10)The participant will be rewarded by giving the badges after all the missions completed. Then, the participant needs to go back to the APi main screen by hitting the "OUT" button.

11)At the APi main screen, the participant can choose "KELUAR" to exit the game.

\section{ANALYSIS AND FINDINGS}

The evaluation results of initial APi prototype interface design were shown in Tables 4 and 5. This evaluation needed the participants which, two lecturers (R1, R2), two gamers (R3, R4) and two graphic designers (R5, R6) responded either agree and disagree with the features in APi interface design. The results stated that the features developed were suitable for the preschool children in terms of colour, fonts and the usage of buttons. However, some of the features needed changes for the position of button to avoid confusion of the functionality. The background of APi interface design needed changes too according to the mission and theme of the game. As stated below, these were the results which, the developer needed to improve on for the next stage in developing high-fidelity APi prototype interface design. 
TABLE IV. RESPONDENTS OF API LOW-FIDELITY PROTOTYPE

\begin{tabular}{|c|c|c|c|c|c|c|}
\hline Criteria & R1 & $\mathbf{R 2}$ & R3 & R4 & R5 & R6 \\
\hline Background Theme (Colour) & $\checkmark$ & $\mathrm{x}$ & $\checkmark$ & $\mathrm{x}$ & $\checkmark$ & $\mathrm{x}$ \\
\hline Background Theme (Images) & $\mathrm{x}$ & $\checkmark$ & $\mathrm{x}$ & $\checkmark$ & $\mathrm{x}$ & $\checkmark$ \\
\hline Fonts (Size) & $\mathrm{x}$ & $\mathrm{x}$ & $\checkmark$ & $\checkmark$ & $\checkmark$ & $\mathrm{x}$ \\
\hline Fonts (Type) & $\checkmark$ & $\mathrm{x}$ & $\mathrm{x}$ & $\mathrm{x}$ & $\checkmark$ & $\checkmark$ \\
\hline Button of “MULA/ KELUAR" (Size of fonts) & $\mathrm{x}$ & $\checkmark$ & $\checkmark$ & $\mathrm{x}$ & $\mathrm{x}$ & $\checkmark$ \\
\hline Button of "MULA/ KELUAR" (Type of fonts) & $\checkmark$ & $\mathrm{x}$ & $\mathrm{x}$ & $\checkmark$ & $\mathrm{x}$ & $\mathrm{x}$ \\
\hline Button of “MULA/ KELUAR” (Animation) & $\checkmark$ & $\checkmark$ & $\checkmark$ & $\checkmark$ & $\checkmark$ & $\checkmark$ \\
\hline Controller Button (Use) & $\mathrm{x}$ & $\mathrm{x}$ & $\checkmark$ & $\mathrm{x}$ & $\checkmark$ & $\mathrm{x}$ \\
\hline Controller Button (Consistency of shape/size) & $\mathrm{x}$ & $\mathrm{x}$ & $\mathrm{x}$ & $\mathrm{x}$ & $\mathrm{x}$ & $\checkmark$ \\
\hline Controller Button (Position) & $\mathrm{x}$ & $\mathrm{x}$ & $\mathrm{x}$ & $\mathrm{x}$ & $\mathrm{x}$ & $\mathrm{x}$ \\
\hline Icon & $\checkmark$ & $\checkmark$ & $\checkmark$ & $\checkmark$ & $\checkmark$ & $\mathrm{x}$ \\
\hline Character (Size) & $\checkmark$ & $\checkmark$ & $\checkmark$ & $\checkmark$ & $\checkmark$ & $\checkmark$ \\
\hline Game Goals & $\checkmark$ & $\checkmark$ & $\checkmark$ & $\checkmark$ & $\checkmark$ & $\checkmark$ \\
\hline Menus (Position) & $\checkmark$ & $\checkmark$ & $\checkmark$ & $\checkmark$ & $\checkmark$ & $\checkmark$ \\
\hline Menus (Colour) & $\mathrm{x}$ & $\checkmark$ & $\checkmark$ & $\checkmark$ & $\checkmark$ & $\checkmark$ \\
\hline Menus (Animation) & $\checkmark$ & $\checkmark$ & $\checkmark$ & $\checkmark$ & $\checkmark$ & $\checkmark$ \\
\hline Features (Activities) & $\checkmark$ & $\checkmark$ & $\checkmark$ & $\checkmark$ & $\checkmark$ & $\checkmark$ \\
\hline Features (Reward) & $\checkmark$ & $\checkmark$ & $\checkmark$ & $\checkmark$ & $\checkmark$ & $\checkmark$ \\
\hline Features (Time) & $\checkmark$ & $\checkmark$ & $\checkmark$ & $\checkmark$ & $\checkmark$ & $\checkmark$ \\
\hline Features (Score) & $\checkmark$ & $\checkmark$ & $\checkmark$ & $\checkmark$ & $\checkmark$ & $\checkmark$ \\
\hline
\end{tabular}

TABLE V. PERCENTAge OF INTEREST ON API DESIGN CRITERIA

\begin{tabular}{|c|c|c|c|}
\hline Criteria & Description & Agree & Disagree \\
\hline Background Theme & $\begin{array}{l}\text { 1. The colour of the background. } \\
\text { 2. The use of images as the background. }\end{array}$ & $\begin{array}{l}50 \\
50\end{array}$ & $\begin{array}{l}50 \\
50\end{array}$ \\
\hline Fonts & $\begin{array}{l}\text { 1. Size of fonts. } \\
\text { 2. Type of fonts. }\end{array}$ & $\begin{array}{l}50 \\
50\end{array}$ & $\begin{array}{l}50 \\
50\end{array}$ \\
\hline Button (MULA, KELUAR) & $\begin{array}{l}\text { 1. Size of fonts. } \\
\text { 2. Type of fonts. } \\
\text { 3. The button in animation style. }\end{array}$ & $\begin{array}{l}50 \\
33 \\
100\end{array}$ & $\begin{array}{l}50 \\
67 \\
0\end{array}$ \\
\hline Controller Button & $\begin{array}{l}\text { 1. The use of button to move the character. } \\
\text { 2. Consistency of shape and size. } \\
\text { 3. Position of button. }\end{array}$ & $\begin{array}{l}33 \\
17 \\
0\end{array}$ & $\begin{array}{l}67 \\
83 \\
100\end{array}$ \\
\hline Icon & 1. The use of icon to deliver the information. & 83 & 17 \\
\hline Character & 1. The size of characters. & 100 & 0 \\
\hline Game Goals & 1. The way of playing and delivering the information. & 100 & 0 \\
\hline Menus & $\begin{array}{l}\text { 1. The position of Menus. } \\
\text { 2. The use of colours. } \\
\text { 3. The button in animation style. }\end{array}$ & $\begin{array}{l}100 \\
83 \\
100\end{array}$ & $\begin{array}{l}0 \\
17 \\
0\end{array}$ \\
\hline Features & $\begin{array}{l}\text { 1. Mission (Activities) } \\
\text { 2. Reward } \\
\text { 3. Time } \\
\text { 4. Score }\end{array}$ & $\begin{array}{l}100 \\
100 \\
100 \\
100\end{array}$ & $\begin{array}{l}0 \\
0 \\
0 \\
0\end{array}$ \\
\hline
\end{tabular}

Meanwhile, Table 5 indicated the percentage of interest on APi design criteria by the respondents. Based on the Cognitive Walkthrough method conducted, there were some suggestions proposed by the participants to improve the APi interface design. Table 4 shows the results of APi prototype that needed improvement. There were few suggestions such as focusing on the usage of button (MULA, KELUAR), controller button, background theme and menus.
The position of buttons should be placed and designed consistently, which were divided into two such as button for player and button for next screen. This was to ensure less confusion towards the use of buttons. Meanwhile, the background themes were changed based on the missions provided. Next, the position, font type and size of menu must be changed to ensure the users easily adapt to the APi interface design. All the changes made in APi low-fidelity prototype 
would help the children to achieve the goals of learning fire safety education with better understanding.

APi high-fidelity prototype interface design was improved through the Cognitive Walkthrough process. As shown in Table 6, these were the interface design of APi that met the user requirements.

TABLE VI. API High-FIDELITY PROTOTYPE INTERFACE DESIGN

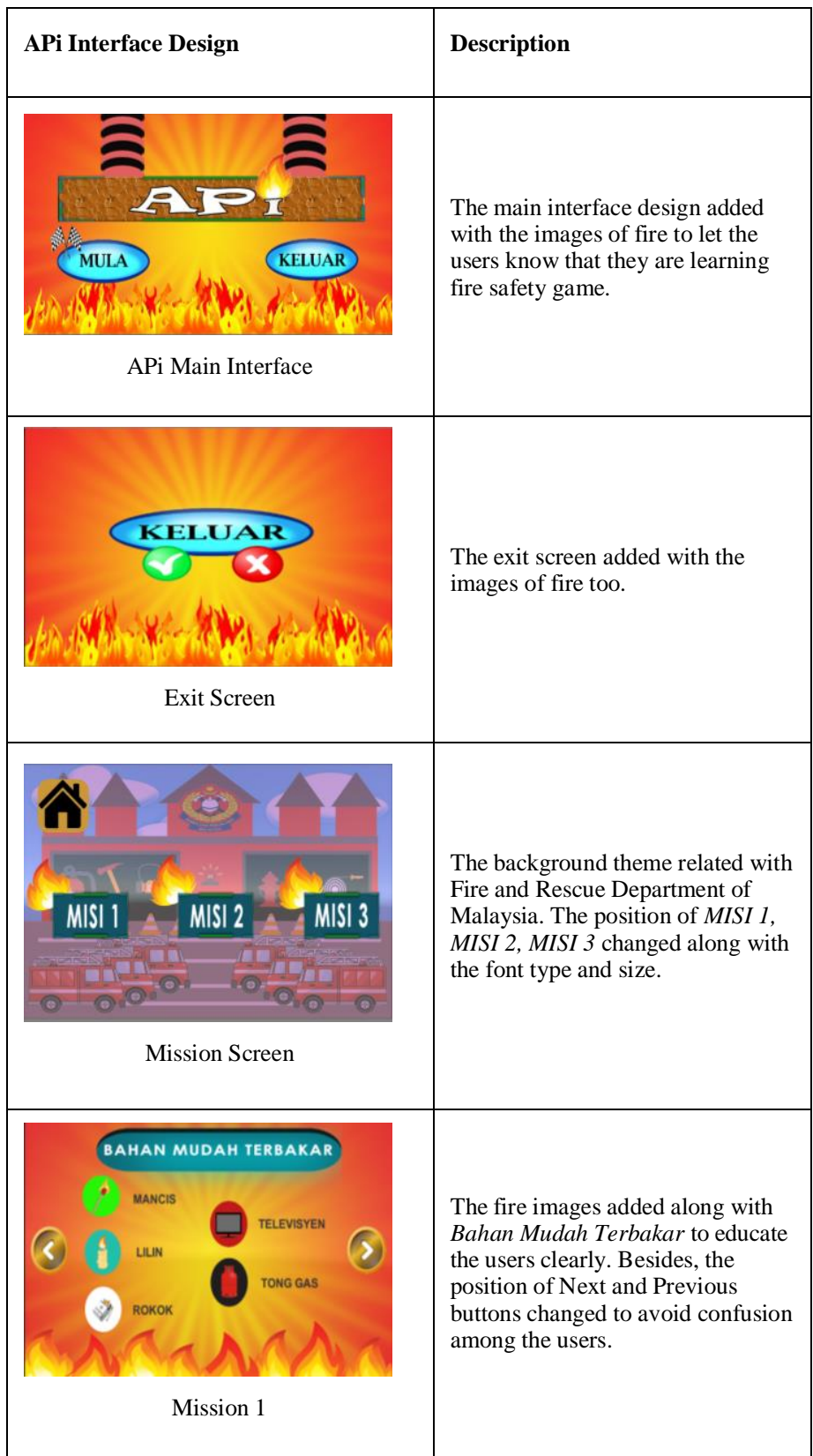

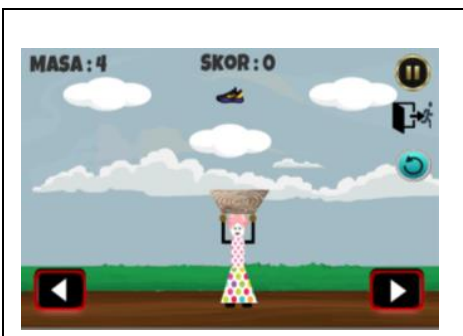

Mission 1 : Gameplay

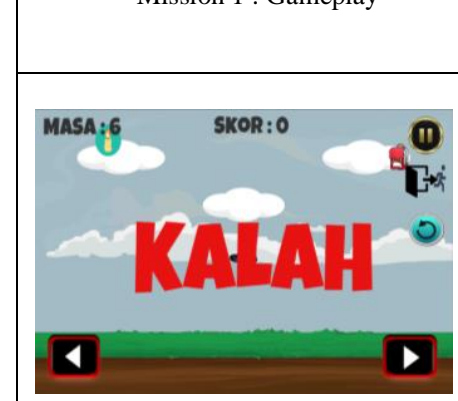

Mission 1

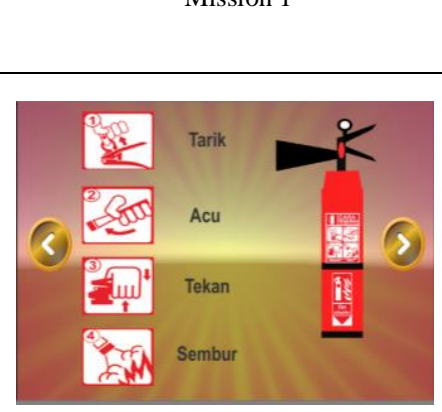

Mission 2 : Instruction

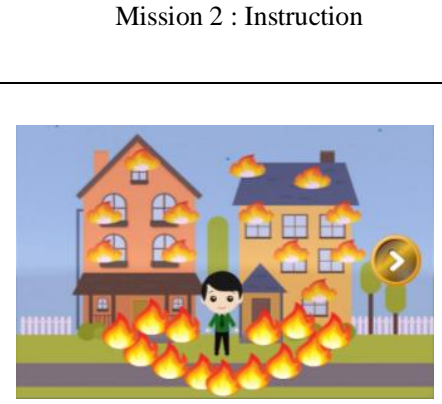

Mission 2 : Instruction

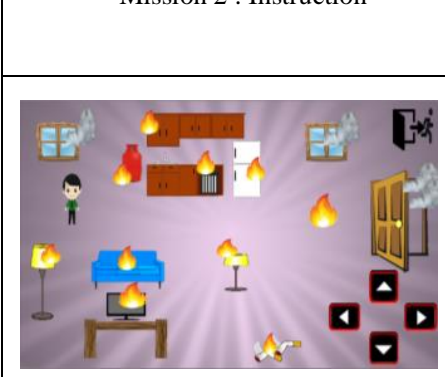

Mission 2 : Gameplay
The controller button changed in terms of design and position. For the design, the controller buttons were fixed to ensure the consistency in every missions. Meanwhile, there were differences between the position of controller buttons and Next, Previous buttons to avoid confusion for the users.

The coding was added using $\mathrm{C \#}$ where if the player gets the wrong items, the screen will show $K A L A H$ (You Lost). Along with the time was fixed too using $\mathrm{C \# \text {. }}$

The position of Next and Previous buttons was fixed to ensure the consistency in every screens of interface.

The background theme changed based on the mission to escape from fire in house. The position of Next button was fixed too.

The controller buttons added with UP and DOWN to control the player movements. The buttons were fixed to ensure the consistency in design and position. 


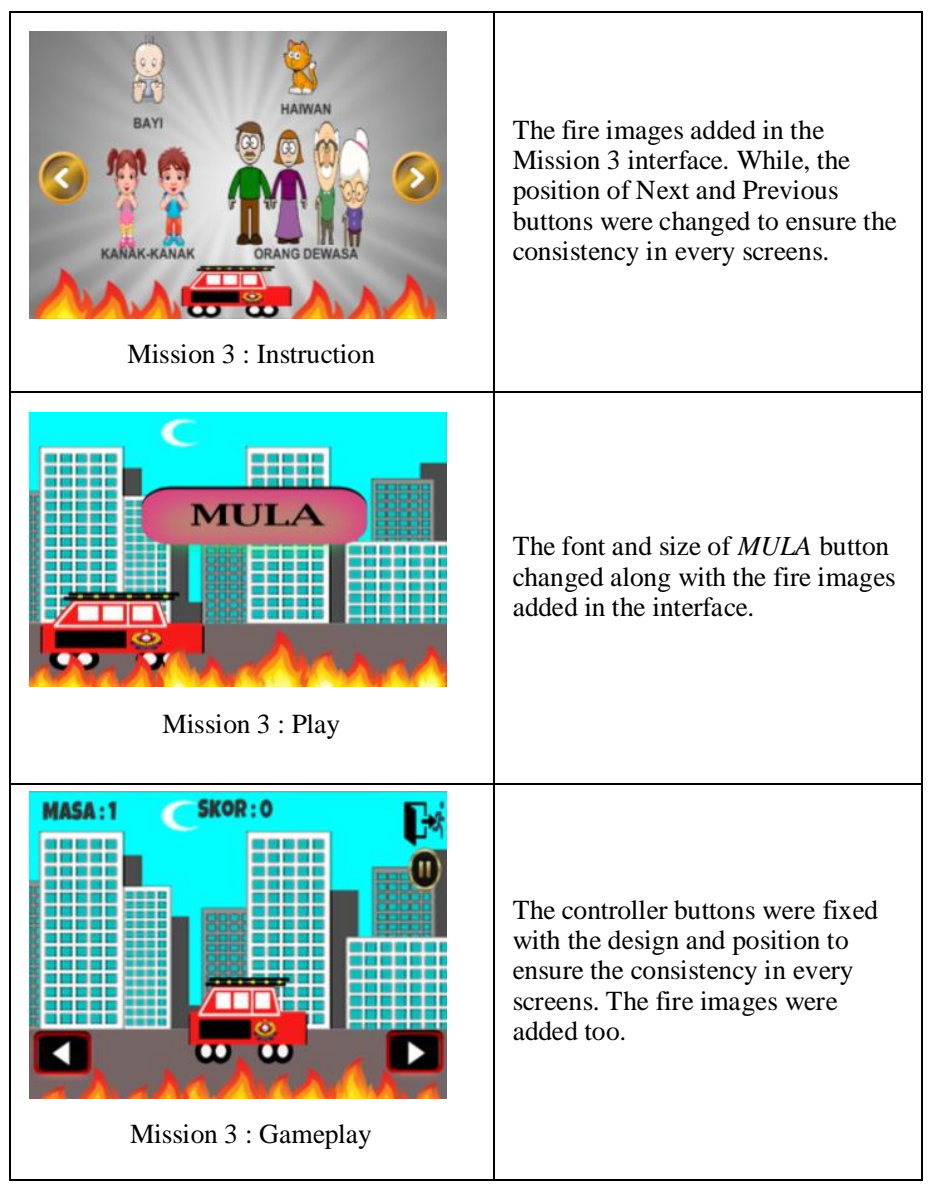

\section{DISCUSSION}

Using virtual simulations and serious games were focused too in learning fire safety education. They offered the users to train with the safe and cost-effective alternative to practice fire safety. The innovative and interactive technology provided for users were highly engaging and immersive to improve firefighting skills such as CAVE (Cave Automatic Virtual Environment) [11]. This method was used to improve the children's motivation by using different interface interaction techniques.

It is crucial to improve children's knowledge in fire safety due to their lack of exposure and practices in following fire situation. By providing tool of learning such as The Great Escape game, the children learned through gaming environment which will stimulate their knowledge and behaviors [12]. In fact, this game provided children to learn fire safety education easily at home with less guidance by gameplay.

The computers, Sony Playstation 2 and Nintendo Wii were used to play firefighting games. Apparently, the comparisons of the gaming purposes were evaluated. However, the games developed were only focusing on entertainment. There were lack of appropriate instructional designs for fire fighter training and educational purposes [22].

Children have limited capabilities of cognitive, psychomotor and behavior towards fire safety issues. There is a need to convey the fire safety education by using suitable technology for children. They can operate and handle the technology well due to the precise capabilities of movements of their hands and bodies [15]. Thus, exposing the children in active learning through gaming environment will encourage them to learn. The engagement towards game-based learning in fire safety educated them on the basic knowledge and skills to escape from fire hazard. It also helped in improving their focuses on learning session.

Thus, by developing the prototype of APi with the use of tablet technology let the children learn effectively on fire safety issues. Increasing the awareness at the early age enhances them to initiate the correct actions while facing real fire situation. The fire awareness helped in reducing the risks of injuries for children. Focusing on how well the children's responses are also affecting their behaviors towards fire safety.

In fact, APi prototype provides the children to navigate the game world and learn basic fire safety skills. In order to develop the APi prototype, the Cognitive Walkthrough method was conducted and tested on the experts. The interface design of APi prototype was evaluated specifically. All the requirements of preschool children were added in the APi highfidelity prototype. It included the elements of multimedia such as audio and animation to attract the preschool children's attention.

Therefore, the criteria of APi prototype mentioned that there was a need to focus on the consistency of buttons used to avoid confusion of the functionality. Concerning the fact that the children were not able to understand English fluently, the APi high-fidelity prototype provided Malay Language as the main language used in the game. The purpose of creating APi prototype using Malay Language was because of the fluency of speaking and understanding of the information delivered to them precisely.

Extending to this research, APi high-fidelity prototype will be tested on the real users who are preschool children. By evaluating the effectiveness of the APi game-based learning, there will be three main aspects being observed such as cognitive, psychomotor skills and behavior towards fire safety education. Their responses will be taken seriously to validate the Model of Game-Based Learning of Fire Safety developed.

\section{CONCLUSION}

The APi interface design could be developed iteratively through the process of Cognitive Walkthrough which involved six experts in evaluating the interface design. This study indicated that the results of APi interface design evaluation is to improve the weakness and meet the user requirements of preschool children. Cognitive Walkthrough method helped in identifying the APi interface design corresponding with the users which consisted of the font, size, position, design of button, menu interface, background theme and functionality of the buttons.

Evaluation resulted in improvements of the weakness in APi low-fidelity prototype that ease the users to understand and play the game with minimal supervision. Using Cognitive Walkthrough method helped to ensure the APi prototype design meet the requirements of preschool children and also the Model of Game-Based Learning in Fire Safety developed. 
This study reinforces the applicability of Cognitive Walkthrough in usability evaluation of APi prototype. By developing a game-based learning of fire safety, in support of three main objectives, which are to meet the need of fire safety education, to develop the game application and to validate the effectiveness of Model Game-Based Learning in Fire Safety. Fire hazard is a growing concern issue in Malaysia which leads people to be injured and may cause death that will affect their lives.

As a result, different forms of learning are needed for preschool children. Fire safety is a difficult skill where the children must show the correct responses in fire hazard situation. Different ages of children carry out the activities by different techniques of problem solving. Thus, providing the emerging game environment may help in creating new paradigm of learning. In order to increase children's motivation and attention spans, advances in teaching and learning methods using other technologies can be applied in learning session for future work. Multi-touch interaction can be implemented for the users to test their abilities in handling technologies.

This research indicated the APi prototype interface design through Cognitive Walkthrough method. Age of learners impacts the system's needs, where they need different learning environment. In the future, gaming elements and functionality of fire safety games should be improved by providing different difficulties in level of activities. Thus, fire safety games help to improve fire safety training skills of children.

\section{ACKNOWLEDGMENT}

This work was supported under Strategic Research Grant of KRA-2018-025, Faculty of Technology \& Information Science, Universiti Kebangsaan Malaysia.

\section{REFERENCES}

[1] Wei, W.J., \& Lee, L.C., "Interactive technology for creativity in early childhood education," Jurnal Teknologi, vol 75, pp. 121-126, 2014

[2] All, A., Nuñez Castellar, E. P., \& Van Looy, J., "Towards a conceptual framework for assessing the effectiveness of digital game-based learning," Computers \& Education, vol 88, pp. 29-37, 2015

[3] Tsai, M. H., Wen, M. C., Chang, Y.L., \& Kang, S. C., "Game-based education for disaster prevention," AI and Society, vol 30, pp. 463-475, 2015

[4] Chin, L. C., \& Effandi Zakaria, "Development and Validation of the Game-Based Learning Module to Enhance Mathematics Achievement, Positive Learning Behaviours and Pro Social Behaviours," Journal of Science And Mathematics Letters, vol 2, pp. 23-31, 2014

[5] Laili Farhana, M. I., Norhayati., B., \& Maizatul, H. M. Y., "A field study of understanding child's knowledge, skills and interaction towards capacitive touch technology (iPad)," 8th International Conference on Information Technology in Asia - Smart Devices Trend: TechnologisingFuture Lifestyle, Proceedings of CITA, pp. 6-10, 2013

[6] Noorhidawati, a., Ghalebandi, S. G., \& Siti Hajar, R., "How Do Young Children Engage with Mobile Apps? Cognitive, Psychomotor, and
Affective Perspective,” Computers \& Education, vol 87, pp. 385-395, 2013

[7] Wook, T. S. M. T., Mohamed, H., Judi, H. M., \& Ashaari, N. S., "Applying cognitive walkthrough to evaluate the design of SPIN interface," Journal of Convergence Information Technology, vol 7, pp. 106-1152012

[8] Ahrens, M., "Smoke Alarms in U.S. Home Fires," Nfpa Fire Analysis and Research Quincy, MA, 2014

[9] Azman, I. \& Mohd Ridwan, A. R., "Performance-based reward administration as an antecedent of job satisfaction: A case study of Malaysia' s fire and rescue agencies," Malaysian Journal of Society and Space, vol 7, pp. 107-118, 2016

[10] Kamarudin, D., Hussain, Y., Applegate, E. B., \& Yasin, M. H. M., “An Ethnographic Qualitative Study On The Malaysian Preschool And Special Needs Children's Home And School Reading Habits," International Journal of Pedagogy and Teacher Education (IJPTE), vol 2, pp. 224-234, 2018

[11] Smith, S., \& Ericson, E., "Using immersive game-based virtual reality to teach fire-safety skills to children," Virtual Reality; vol 13, pp. 87-99, 2008

[12] Morrongiello, B. a., Schwebel, D. C., Bell, M., Stewart, J. \& Davis, A. L., "An evaluation of The Great Escape: Can an interactive computer game improve young children's fire safety knowledge and behaviors?," Health Psychology, vol 31, pp. 496-502, 2012

[13] He, Q., Hong, X., Zhao, G., \& Huang, X., “An Immersive Fire Training System Using Kinect," Proceedings of the 2014 ACM International Joint Conference on Pervasive and Ubiquitous Computing: Adjunct Publication, vol 14, pp. 231-234, 2014

[14] Singh, D. K. A., Ab Rahman, N. N. A. A., Rajikan, R., Zainudin, A., Mohd Nordin, N. A., Karim, Z. A., \& Yee, Y. H., "Balance and motor skills among preschool children aged 3 to 4 years old," Malaysian Journal of Medicine and Health Sciences, vol 11, pp. 63-68, 2015

[15] Anthony, L., Brown, Q., Nias, J., Tate, B., \& Mohan, S., "Interaction and recognition challenges in interpreting children's touch and gesture input on mobile devices," Proceedings of the 2012 ACM International Conference on Interactive Tabletops and Surfaces - ITS '12, pp. 225, 2012

[16] Towers, B., "Children 's knowledge of bushfire emergency response," International Journal of Wildland Fire, vol 24, pp. 179-189, 2015

[17] Jadhav, D., Bhutkar, G., \& Mehta, V., "Usability evaluation of messenger applications for Android phones using cognitive walkthrough," Proceedings of the 11th Asia Pacific Conference on Computer Human Interaction - APCHI '13, pp. 9-18, 2013

[18] Rieman, J., Franzke, M., \& Redmiles, D., "Usability Evaluation with the Cognitive Walkthrough," Conference Companion on Human Factors in Computing Systems, 1995

[19] Zaini, N.A., Noor, S.F.M, Wook, T.S.M.T, "The User Requirements of Game-Based Learning in Fire Safety for Preschool Children," Journal of Advanced Science Letters, vol 24, pp. 7795-7799, 2018

[20] Abdul Jabbar, A. I. \& Felicia, P., "Gameplay Engagement and Learning in Game-Based Learning: A Systematic Review," Review of Educational Research, vol 85, pp. 740-779, 2015

[21] Shi, Y.-R. \& Shih, J.-L., "Game Factors and Game-Based Learning Design Model," International Journal of Computer Games Technology, pp. 1-11, 2015

[22] Williams-Bell, F. M., Kapralos, B., Hogue, A., Murphy, B. M. \& Weckman, E. J., "Using Serious Games and Virtual Simulation for Training in the Fire Service: A Review," Fire Technology, vol 51, 2015 